\title{
Shear Correction Factor Effects on Functionally Graded Materials (FGMs) Beams using Discrete Shear Gap (DSG) Element
}

\author{
Imam Jauhari Maknun ${ }^{1 *}$, Salfa Zarfatina ${ }^{1}$ \\ ${ }^{1}$ Department of Civil and Environmental Engineering, Faculty of Engineering, Universitas Indonesia, \\ Kampus UI Depok, Depok 16424, Indonesia
}

\begin{abstract}
Materials and computational methods are essential to support the development of infrastructure. Composite material has been used in many applications; in the laminated composite, failure due to excessive interlaminar stresses between two materials causes delamination. Thus, functionally graded materials (FGMs) have emerged. A numerical computation such as the finite element method (FEM) is widely used to support the analysis of FGMs in structural applications. The discrete shear gap DSG element is developed using Timoshenko beam theory, where the shear correction factor is used in their formulation. The shear correction factor is assumed to be constant in many applications; thus, it is valid for isotropic homogenous material. However, the effect of shear deformation significantly impacts the results of the FGMs beam, so the shear correction factor cannot be considered constant. Therefore, this paper presents the shear correction factor effect on static analysis of FGMs beam using DSG element. Various boundary conditions with length thickness ratio $(L / h=4)$ are evaluated. The DSG element yields good results in FGMs beam for different power-law index ratios. Furthermore, the DSG element result shows that the higher the modulus of elasticity ratio of the top-to-bottom material, the further the difference between $k$ FGMs and $k=5 / 6$ (constant). The DSG element can provide precise results without shear locking.
\end{abstract}

Keywords: $\quad$ Composite; DSG; FEM; FGMs; Shear correction factors

\section{Introduction}

Composites are the combination of materials selected based on the variety of the physical properties of each constituent material. They are combined to produce a new material with unique properties compared to those of the primary material. The application of composite material in beam structures can be found in Benbouras et al. (2017). Delamination remains a large problem in laminated composites (Reddy, 2006). In an attempt to solve this problem, new composite materials, called Functionally Graded Materials (FGMs), were first proposed in 1984 by a group of materials scientists in Japan.

The material properties vary gradually and continuously from one surface to another according to the given function. The gradation of material properties through thickness avoids sudden changes in stress distribution. In general, this material is a mixture of ceramics on the top and metal at the bottom. The main benefit of using this material is that it can withstand extreme situations like a high-temperature environment. The use of this material increases rapidly in many applications. Numerical analysis such as FEM is desired 
to support the development of FGMs.

FEM is one of the numerical techniques used to support structural analysis. Many papers deal with the recent development of FEM in plate and shell structures for isotropic material (Katili et al., 2014; Maknun et al., 2016; Irpanni et al., 2017; Katili et al., 2017; Katili et al., 2018a; Katili et al., 2018b; Katili et al., 2019a). The results of FEM for the composite material can be found in (Katili et al., 2015; Maknun et al., 2015; Katili et al., 2018c; Katili et al., 2018d; Katili et al., 2019b; Maknun et al., 2020). From the results, FEM can support the analysis of plate and shell structures in isotropic and composite materials with accurate results.

FEM performs very well in calculating FGMs beam (Simsek, 2009; Thai and Vo 2012; Nguyen et al., 2013, Aghazadeh et al., 2014; Jing et al., 2016; Katili and Katili 2020). Many beam elements have been proposed for application in beam structures using either Euler Bernoulli's or Timoshenko's (Timoshenko, 1921; Timoshenko, 1922) beam theories. The beam element developed using Euler Bernoulli's beam theory needs $\mathrm{C}^{1}$ continuity and can only be used for thin beam structures. Timoshenko beam elements were proposed to overcome these limitations. Beam elements developed from Timoshenko beam theory can be used for thin to thick beam structures and need only $\mathrm{C}^{0}$ continuity. However, the shear locking phenomenon exists in Timoshenko beam elements. There are several methods to overcome this phenomenon. One of these is the discrete shear gap (DSG) method proposed by Bletzinger et al. (2000).

For the beam element developed from Timoshenko beam theory, such as the DSG element, the shear correction factor is one of the necessary terms. This factor obtained from the shear strain energy from equilibrium equations equated to the shear strain energy obtained from the constitutive equation (Meena et al., 2012). In isotropic rectangular beams, this factor is equal to $k=5 / 6$. For many applications of FGMs in beam structures, the shear correction factor is assumed to be constant. This factor is not constant for nonisotropic material like FGMs. This factor has a significant effect when analyzing thick beam problems in which the shear energy is crucial, which many papers have dealt with. (Timoshenko, 1922; Nguyen et al., 2008; Hosseini-Hashem et al. 2010).

This paper aims to study the effect of the shear correction factor on the FGMs beam by using the DSG element. The equation for the shear correction factor is taken from Meena et al. (2012). FGMs beams with various boundary conditions and length thickness ratios $(L / h$ = 4) are evaluated. Different power-law indexes $(n)$ are also assessed to understand the convergence behavior of the DSG element in the FGMs beam.

\section{Methods}

\subsection{FGM Beams}

According to the given function, FGMs are materials whose mechanical properties change slowly and continuously from one surface to another. One application of this FGMs is for beam structures. The FGMs beam is illustrated as follows:

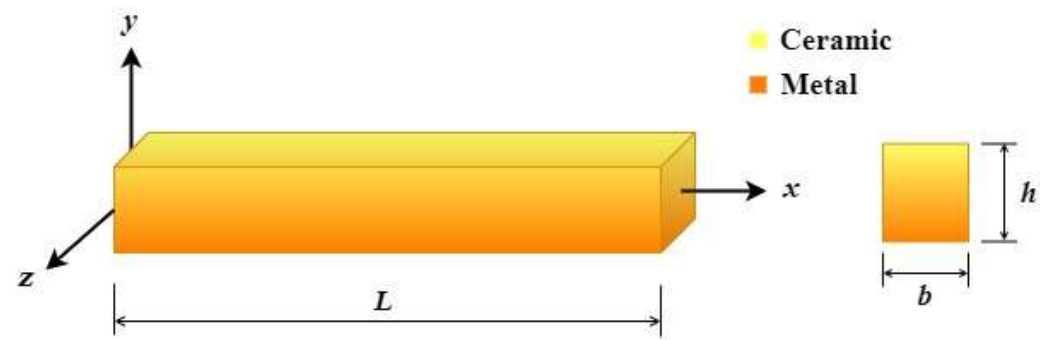

Figure 1 FGMs beams in cartesian coordinates 
The material properties of FGMs change according to the thickness of the beam (i.e., change in the $y$-axis). In the perfect form of FGMs, the material properties change continuously and gradually according to various patterns, such as exponential law, power law, and sigmoid law (Malikan and Eremeyev, 2020). In this study, the power law is employed, and the following are the volume fraction functions of the FGMs by using the power law (P-FGMs):

$$
V_{P}(y)=\left(\frac{2 y+h}{2 h}\right)^{n} \quad-\frac{1}{2} h \leq y \leq \frac{1}{2} h
$$

where $h$ is the thickness of the beam, $y$ is the coordinate along the thickness direction, $n$ is the power-law index for the FGM, and $V_{P}$ is the volume fraction along the thickness direction.

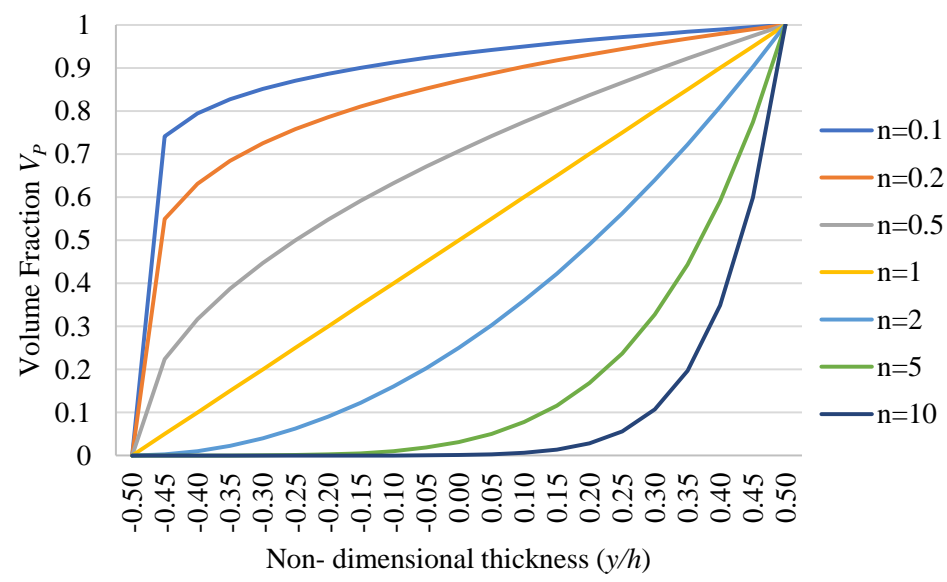

Figure 2 Distribution of material volume fraction along with beam thickness (P-FGMs)

The effective properties of the FGMs is expressed by:

$$
P(y)=P_{t} V_{p}(y)+P_{b}\left(1-V_{p}(y)\right)
$$

The modulus of elasticity $(E)$ of the beam is then expressed by:

$$
E(y)=E_{t} V_{p}(y)+E_{b}\left(1-V_{p}(y)\right)
$$

where $E_{t}$ denotes the material properties at the top of the beam and $E_{b}$ means the material properties at the bottom of the beam. In the FGMs beam, ceramic is used on the top and metal at the bottom, as shown in Figure 1. The deformation of the beam in FGMs application is expressed by Katili and Katili (2020) as:

$$
\begin{aligned}
& u(x, y)=u_{a}(x)-y \theta(x) \\
& v(x, y)=v(x)
\end{aligned}
$$

where $u(x, y)$ is the displacement of the beam in the $x-y$ plane, $u_{a}(x)$ is the axial displacement function, $\theta(x)$ is the rotation function for bending, and $v(x, y)$ is the vertical displacement of the beam. Then, the axial and transverse shear strains $(\varepsilon$ dan $\gamma$ ) at the point $x$ along the beam in the $x-y$ plane are as follows:

where:

$$
\varepsilon(x, y)=\frac{\partial u(x, y)}{\partial x}=e(x)+y \chi(x)
$$

$$
\begin{gathered}
e(x)=\frac{d u_{a}(x)}{d x} \\
\chi(x)=-\frac{\mathrm{d} \theta(x)}{d x}
\end{gathered}
$$


Transverse Shear Strain:

$$
\gamma(x)=\frac{d v(x)}{d x}-\theta(x)
$$

The material of the FGMs beam obeys Hooke's law; thus, the relationship between normal stress and normal strain is as follows:

$$
\sigma=E(y) \varepsilon(x, y)=E(y) e(x)+E(y) y \chi(x)
$$

Then the relationship between shear stress and transverse shear strain is as follows:

$$
\tau=G(y) \gamma(x)
$$

Shear modulus $G(y)$ is stated as follows:

$$
G(y)=\frac{E(y)}{2(1+v)}
$$

with $v$ as Poisson's ratio, which is assumed to be constant in this paper.

\subsection{DSG Element}

The discrete shear gap (DSG) method proposed by Bletzinger et al. (2000) suggests overcoming the shear locking phenomenon in Timoshenko beam elements. This method is performed by modifying the shear strain formulation in conventional FEM to be DSG shear strain. The axial displacement $u$, the vertical displacement $v$, and the rotation $\theta$ are interpolated as follows:

with

$$
\begin{aligned}
& u(x)=\left\langle\begin{array}{llllll}
N_{1} & 0 & 0 & N_{2} & 0 & 0
\end{array}\right\rangle\left\{u_{n}\right\} \\
& v(x)=\left\langle\begin{array}{llllll}
0 & N_{1} & 0 & 0 & N_{2} & 0
\end{array}\right\rangle\left\{u_{n}\right\} \\
& \theta(x)=\left\langle\begin{array}{llllll}
0 & 0 & N_{1} & 0 & 0 & N_{2}
\end{array}\right\rangle\left\{u_{n}\right\}
\end{aligned}
$$

$$
\begin{aligned}
& N_{1}=1-\frac{x}{L} \quad ; \quad N_{2}=\frac{x}{L} \\
& \left\langle u_{n}\right\rangle=\left\langle\begin{array}{llllll}
u_{1} & v_{1} & \theta_{1} & u_{2} & v_{2} & \theta_{2}
\end{array}\right\rangle
\end{aligned}
$$

Introducing Equation 12 to Equation 6 yields:

$$
\begin{aligned}
& e=\frac{d u_{a}(x)}{d x}=\left\langle B_{a}\right\rangle\left\{u_{n}\right\} \\
& \left\langle B_{a}\right\rangle=\left\langle\begin{array}{llllll}
-\frac{1}{L} & 0 & 0 & \frac{1}{L} & 0 & 0
\end{array}\right\rangle
\end{aligned}
$$

Introducing Equation 12 to Equation 7 yields:

$$
\begin{aligned}
& \chi=-\frac{d \theta(x)}{d x}=\left\langle B_{b}\right\rangle\left\{u_{n}\right\} \\
& \left\langle B_{b}\right\rangle=\left\langle\begin{array}{llllll}
0 & 0 & -\frac{1}{L} & 0 & 0 & \frac{1}{L}
\end{array}\right\rangle
\end{aligned}
$$

Following Katili (2017), the modification shear strain in the DSG element is expressed as:

$$
\begin{aligned}
& \gamma=\left\langle B_{s}\right\rangle\left\{u_{n}\right\} \\
& \left\langle B_{s}\right\rangle=\left\langle\begin{array}{llllll}
0 & -\frac{1}{L} & -\frac{1}{2} & 0 & \frac{1}{L} & -\frac{1}{2}
\end{array}\right\rangle
\end{aligned}
$$

The stiffness matrix of DSG elements in FGMs beams is composed of the sum obtained from axial, flexural, couple axial bending, and internal shear energies, as follows: 
1. Axial Energy

$$
\begin{aligned}
& \Pi_{\mathrm{int}}^{a}=\frac{1}{2} D_{a} \int_{0}^{L} e^{2} d x \\
& \Pi_{\mathrm{int}}^{a}=\frac{1}{2} D_{a} \int_{0}^{L}\left\langle u_{n}\right\rangle\left\{B_{a}\right\}\left\langle B_{a}\right\rangle\left\{u_{n}\right\} d x \\
& {\left[k_{a}\right]=D_{a} \int_{0}^{L}\left\{B_{a}\right\}\left\langle B_{a}\right\rangle d x}
\end{aligned}
$$

2. Bending Energy

3. Shear Energy

$$
\begin{aligned}
& \Pi_{\mathrm{int}}^{b}=\frac{1}{2} D_{b} \int_{0}^{L} \chi^{2} d x \\
& \Pi_{\mathrm{int}}^{b}=\frac{1}{2} D_{b} \int_{0}^{L}\left\langle u_{n}\right\rangle\left\{B_{b}\right\}\left\langle B_{b}\right\rangle\left\{u_{n}\right\} d x \\
& {\left[k_{b}\right]=D_{b} \int_{0}^{L}\left\{B_{b}\right\}\left\langle B_{b}\right\rangle d x}
\end{aligned}
$$

$$
\begin{aligned}
& \Pi_{\mathrm{int}}^{s}=\frac{1}{2} D_{s} \int_{0}^{L} \gamma^{2} d x \\
& \Pi_{\mathrm{int}}=\frac{1}{2} D_{s} \int_{0}^{L}\left\langle u_{n}\right\rangle\left\{B_{s}\right\}\left\langle B_{s}\right\rangle\left\{u_{n}\right\} d x \\
& {\left[k_{s}\right]=D_{s} \int_{0}^{L}\left\{B_{s}\right\}\left\langle B_{s}\right\rangle d x}
\end{aligned}
$$

4. Couple Axial-Bending Energy

$$
\begin{aligned}
& \Pi_{\mathrm{int}}^{a b}=\frac{1}{2} D_{a b} \int_{0}^{L} e \chi d x+\frac{1}{2} D_{a b} \int_{0}^{L} \chi e d x \\
& \Pi_{\mathrm{int}}^{a b}=\frac{1}{2} D_{a b}\left\{\int_{0}^{L}\left\langle u_{n}\right\rangle\left\{B_{a}\right\}\left\langle B_{b}\right\rangle\left\{u_{n}\right\} d x+\int_{0}^{L}\left\langle u_{n}\right\rangle\left\{B_{b}\right\}\left\langle B_{a}\right\rangle\left\{u_{n}\right\} d x\right\} \\
& {\left[k_{a b}\right]=D_{a b} \int_{0}^{L}\left\{B_{a}\right\}\left\langle B_{b}\right\rangle d x}
\end{aligned}
$$

where:

$$
\begin{aligned}
& D_{a}=\int_{A} E(y) d A=b h\left(\frac{E_{t}-E_{b}}{n+1}+E_{t}\right) \\
& D_{b}=\int_{A} y^{2} E(y) d A=b h^{3}\left(\frac{\left(n^{2}+n+2\right)\left(E_{t}-E_{b}\right)}{4(n+1)(n+2)(n+3)}+\frac{E_{b}}{12}\right) \\
& D_{s}=k \int_{A} G(y) d A=k b h G(y) \\
& D_{a b}=\int_{A} y E(y) d A=b h^{2}\left(\frac{n\left(E_{t}-E_{b}\right)}{2(n+1)(n+2)}\right)
\end{aligned}
$$

The combined stiffness matrix of DSG elements in FGMs beams is obtained by adding up each of the axial, flexural, axial-bending, and shear stiffness matrices, as follows: 


$$
[k]=\left[k_{a}\right]+\left[k_{b}\right]+\left[k_{s}\right]+\left[k_{a b}\right]+\left[k_{a b}\right]^{T}
$$

Then, the following is the external energy equation in the DSG element beam:

$$
\Pi_{e x t}^{e}=\left\langle u_{n}\right\rangle\left\{f_{n}\right\}
$$

Then, the vector component $\left\langle f_{n}\right\rangle$ can be expressed as follows:

$$
\left\langle f_{n}\right\rangle=f_{0}\left\langle\begin{array}{llllll}
0 & \frac{1}{2} L & \frac{1}{12} L^{2} \quad 0 & \frac{1}{2} L & -\frac{1}{12} L^{2}
\end{array}\right\rangle
$$

\subsection{Shear Correction Factors}

The shear correction factor improves the ideal shear stiffness. For homogeneous material properties, the shear correction factor is constant and depends on the geometry of the beam cross-sectional area. For FGMs, following Meena et al. (2012), the shear correction factor ( $k F G M s$ ) can be written as follows:

$$
k F G M s=\frac{1}{\int_{-h / 2}^{h / 2}\left(\frac{E(y)}{2(1+v)}\right) d y}\left[\int_{-h / 2}^{h / 2} \frac{\left[\int_{-h / 2}^{y}\left(\frac{E(y)}{1-v^{2}} \beta_{11}+\frac{v E(y)}{1-v^{2}} \beta_{12}+y \frac{E(y)}{1-v^{2}} \delta_{11}+y \frac{v E(y)}{1-v^{2}} \delta_{12}\right) d y\right.}{\frac{E(y)}{2(1+v)}} d y\right]^{-1}
$$

\section{Results and Discussion}

The FGMs beams with various boundary conditions and length thickness ratios $(L / h=$ 4 thick beam) are evaluated to understand the performance of the DSG element. Moreover, the effect of a shear correction factor on the convergence of the FGMs beam is evaluated. Different power-law index ratios and two moduli of elasticity ratios of the top-to-bottom material (Et/Eb) are assessed.

\subsection{Case with $E t / E b=0.35$}

The first case used to evaluate the effect of the shear correction factor is an FGMs beam (Figure 3) with $E t / E b=0.35$. The bottom surface of the beam uses zirconia $\left(\mathrm{ZrO}_{2}\right)$, a material with an elastic modulus of $200 \mathrm{GPa}$. The top surface of the beam is aluminum (Al), which has an elastic modulus of $70 \mathrm{GPa}$. Poisson's ratio is assumed to be a constant 0.3 , and distributed load is set at $q=1 \mathrm{kN} / \mathrm{m}$. This case was investigated for several support types: hinged-roll, hinged-hinged, clamped-roll, clamped-hinged, clamped-free, and clampedclamped. Moreover, the beam structures were discretized into number of elements (NELT) $=2,4,8,16,32,64$, and 128 elements. The results acquired through the use of Timoshenko beam theory (TBT) and higher order shear deformation theory (HOSDT) are used as a comparison to the proposed model.

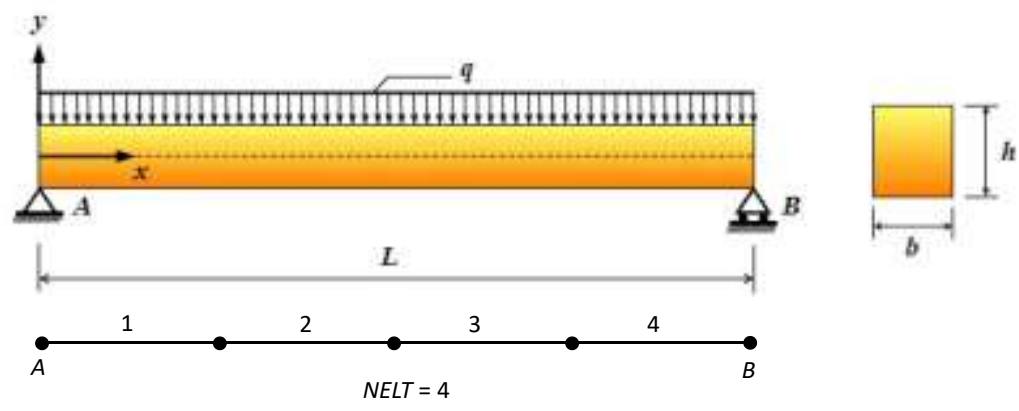

Figure 3 Hinged-roll beams 
The comparison of the displacement results between the constant shear correction factor $(k=5 / 6)$ and the shear correction factor $k$ FGMs for the hinged-roll beam with $L / h=$ 4 and different power-law index $(n)$ are shown in Tables 1 and 2 and Figure 4 . It was found that the vertical displacement is close to the results given by HOSDT. These results indicate that deflection decreases with increasing power-law index. This is because it reduces flexibility while increasing the power-law index, which decreases the metallic volume fraction. Similar results were found for $k=5 / 6$ and $k$ FGMs. The small modulus of the elasticity ratio of the top-to-bottom materials has a marginal effect on the displacement of the hinged-roll beam with $L / h=4$.

Table 1 Convergence of vertical displacement for hinged-roll with $k=5 / 6$

\begin{tabular}{|c|c|c|c|c|c|c|c|c|c|}
\hline \multirow{2}{*}{$\begin{array}{c}\text { Power } \\
\text { Law } \\
\text { Index }(n)\end{array}$} & \multicolumn{7}{|c|}{ Numbers of Element (NELT) } & \multirow{2}{*}{$\begin{array}{c}\text { TBT } \\
\text { (Simsek, } \\
\text { 2009) }\end{array}$} & \multirow{2}{*}{$\begin{array}{c}\text { HOSDT } \\
\text { (Simsek, } \\
2009)\end{array}$} \\
\hline & 2 & 4 & 8 & 16 & 32 & 64 & 128 & & \\
\hline 0 & 0.95600 & 1.10600 & 1.14350 & 1.15288 & 1.15522 & 1.15580 & 1.15595 & 1.13002 & 1.15578 \\
\hline 0.2 & 0.71859 & 0.83099 & 0.85909 & 0.86612 & 0.86787 & 0.86831 & 0.86842 & 0.84906 & 0.87145 \\
\hline 0.5 & 0.60391 & 0.69908 & 0.72287 & 0.72881 & 0.73030 & 0.73067 & 0.73077 & 0.71482 & 0.73264 \\
\hline 1 & 0.53044 & 0.61473 & 0.63581 & 0.64108 & 0.64239 & 0.64272 & 0.64280 & 0.62936 & 0.64271 \\
\hline 2 & 0.47255 & 0.54808 & 0.56697 & 0.57169 & 0.57287 & 0.57316 & 0.57324 & 0.56165 & 0.57142 \\
\hline 5 & 0.41382 & 0.47993 & 0.49645 & 0.50058 & 0.50162 & 0.50188 & 0.50194 & 0.49176 & 0.49978 \\
\hline 10 & 0.38173 & 0.44242 & 0.45760 & 0.46139 & 0.46234 & 0.46258 & 0.46264 & - & 0.46263 \\
\hline
\end{tabular}

Table 2 Convergence of vertical displacement for hinged-roll with $k$ FGMs

\begin{tabular}{|c|c|c|c|c|c|c|c|c|c|}
\hline \multirow{2}{*}{$\begin{array}{c}\text { Power } \\
\text { Law } \\
\text { Index }(n)\end{array}$} & \multicolumn{7}{|c|}{ Numbers of Element (NELT) } & \multirow{2}{*}{$\begin{array}{c}\text { TBT } \\
\text { (Simsek, } \\
2009)\end{array}$} & \multirow{2}{*}{$\begin{array}{c}\text { HOSDT } \\
\text { (Simsek, } \\
2009)\end{array}$} \\
\hline & 2 & 4 & 8 & 16 & 32 & 64 & 128 & & \\
\hline 0 & 0.95600 & 1.10600 & 1.14350 & 1.15287 & 1.15522 & 1.15580 & 1.15595 & 1.13002 & 1.15578 \\
\hline 0.2 & 0.72140 & 0.83380 & 0.86190 & 0.86893 & 0.87068 & 0.87112 & 0.87123 & 0.84906 & 0.87145 \\
\hline 0.5 & 0.60606 & 0.70122 & 0.72502 & 0.73096 & 0.73245 & 0.73282 & 0.73292 & 0.71482 & 0.73264 \\
\hline 1 & 0.53067 & 0.61496 & 0.63603 & 0.64130 & 0.64262 & 0.64295 & 0.64303 & 0.62936 & 0.64271 \\
\hline 2 & 0.47087 & 0.54641 & 0.56529 & 0.57001 & 0.57119 & 0.57149 & 0.57156 & 0.56165 & 0.57142 \\
\hline 5 & 0.41176 & 0.47787 & 0.49440 & 0.49853 & 0.49957 & 0.49982 & 0.49989 & 0.49176 & 0.49978 \\
\hline 10 & 0.38054 & 0.44123 & 0.45640 & 0.46020 & 0.46114 & 0.46138 & 0.46144 & - & 0.46263 \\
\hline
\end{tabular}

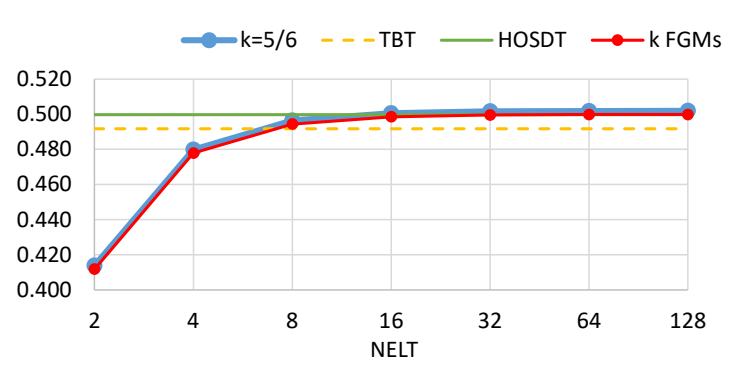

(a)

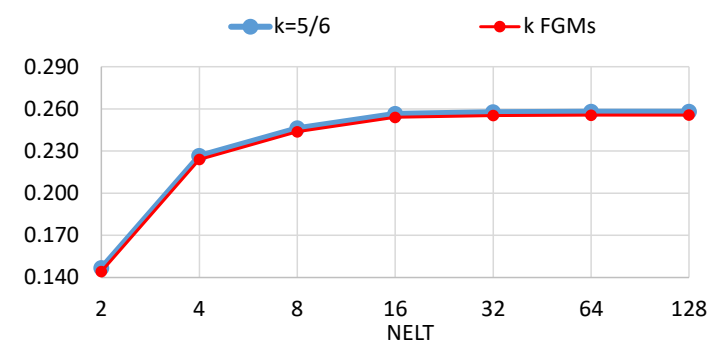

(c)

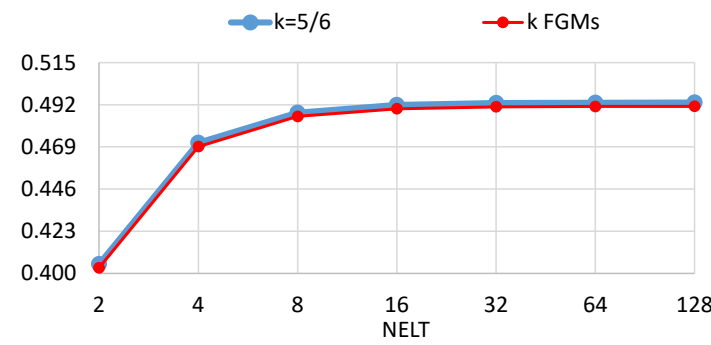

(b)

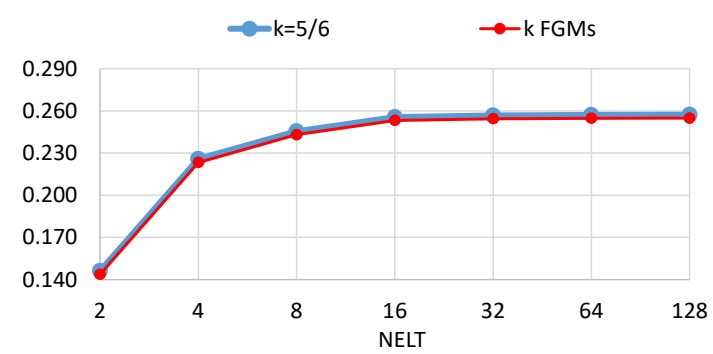

(d) 


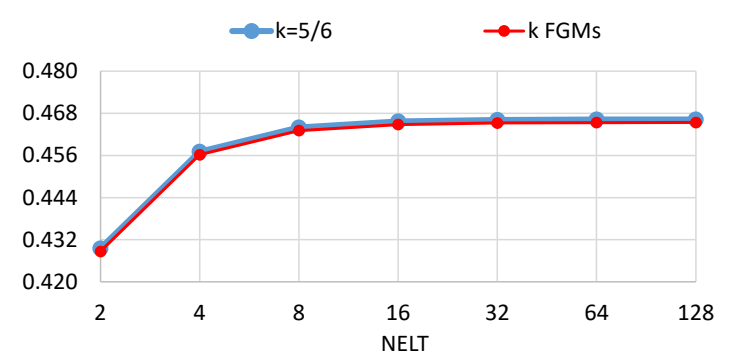

(e)

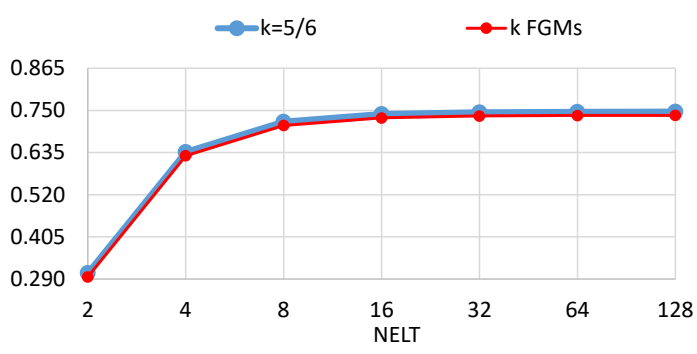

(f)

Figure 4 The convergence of the vertical displacement for $n=5$ and ratio $E t / E b=0.35$ on six different supports with: (a) hinged-roll; (b) hinged-hinged; (c) clamped-roll; (d) clamped-simple; (e) clamped-free; and (f) clamped-clamped

Table 3 presents the displacement error by using the constant shear correction factor $(k=5 / 6)$ compared with $k$ FGMs for six types of supports. It can be seen that the largest error occurs in the clamped-clamped support, and the smallest error occurs in the clampedfree support. This is because shear deformation energy is the greatest in the clampedclamped support, and the smallest amount of energy occurs in the clamped-free support, as shown in Table 4. It was found that the clamped-clamped shear energy is $46.48 \%$ of the total energy of the structures for thick beams.

Table 3 The error of displacement $(E t / E b=0.35$ and $L / h=4)$

\begin{tabular}{lc}
\hline \multicolumn{1}{c}{ Support } & Error (\%) \\
\hline hinged-roll & 0.411 \\
hinged- hinged & 0.418 \\
clamped -roll & 0.937 \\
clamped -simple & 0.938 \\
clamped-free & 0.184 \\
clamped - clamped & 1.394 \\
\hline
\end{tabular}

Table 4 Percentage of shear energy on total energy $(E t / E b=0.35$ and $L / h=4)$

\begin{tabular}{lrcr}
\hline \multicolumn{1}{c}{ Support } & Total Energy & Shear Energy & $\begin{array}{c}\text { \% of shear } \\
\text { energy }\end{array}$ \\
\hline hinged-roll & $3.690 \mathrm{E}-11$ & $4.665 \mathrm{E}-12$ & 12.642 \\
hinged- hinged & $3.623 \mathrm{E}-11$ & $4.665 \mathrm{E}-12$ & 12.875 \\
clamped -roll & $1.759 \mathrm{E}-11$ & $5.469 \mathrm{E}-12$ & 31.089 \\
clamped -simple & $1.754 \mathrm{E}-11$ & $5.457 \mathrm{E}-12$ & 31.119 \\
clamped-free & $2.121 \mathrm{E}-10$ & $1.866 \mathrm{E}-11$ & 8.800 \\
clamped - clamped & $1.004 \mathrm{E}-11$ & $4.665 \mathrm{E}-12$ & 46.483 \\
\hline
\end{tabular}

\subsection{Case with $E t / E b=20$}

The second case of FGMs beams is taken from Meena et al. (2012). In this case, the extreme value of $E t / E b=20(E t=1400 \mathrm{GPa}, E b=70 \mathrm{GPa})$ is evaluated. As in the first case, $L / h=4$, and the Poisson's ratio constant value of 0.3 is employed. Several types of supports were used: hinged-roll, hinged-hinged, clamped-roll, clamped-hinged, clamped-free, and clamped-clamped. Moreover, the beam structures were discretized into number of elements $(N E L T)=2,4,8,16,32,64$, and 128 elements.

Figure 5 presents the results of maximum displacement for $k=5 / 6$ and $k$ FGMs. From the results, it is shown that the differences are significant. This is due to the difference in 
modulus elasticity affecting the value of $k$. Therefore, for FGMs application, it is necessary to use $k$ obtained by FGMs theory for thick beams when the value of $E t / E b$ is important.

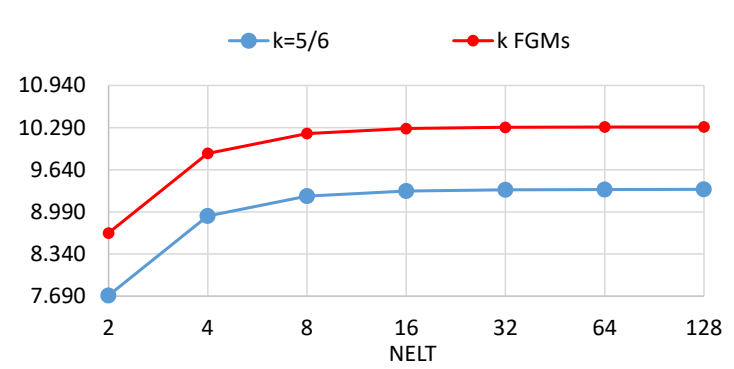

(a)

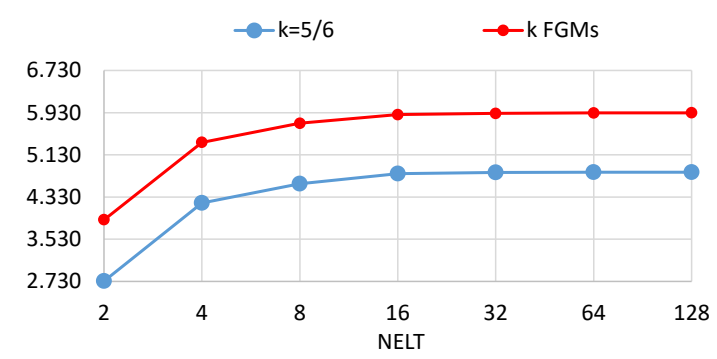

(c)

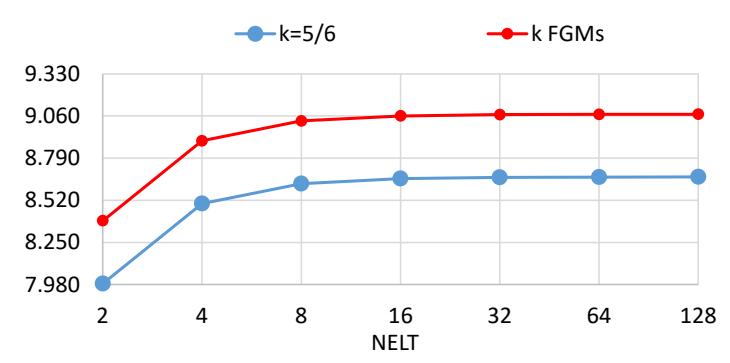

(e)

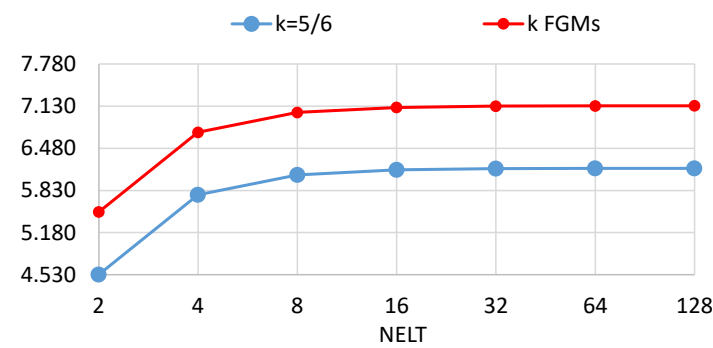

(b)

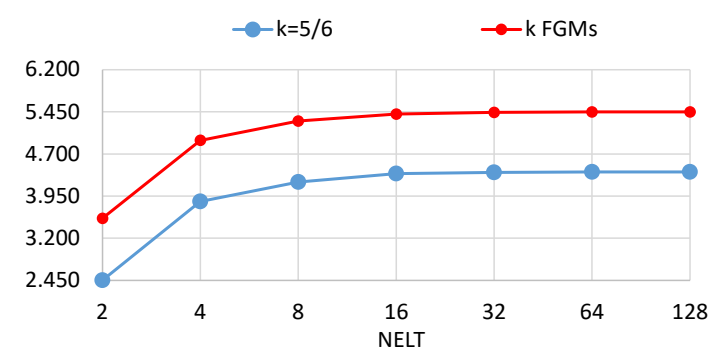

(d)

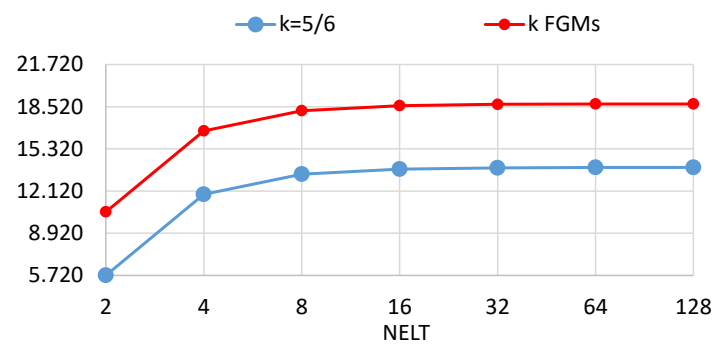

(f)

Figure 5 The convergence of the vertical displacement for $n=10$ and ratio $E t / E b=20$ on six different supports with (a) hinged-roll; (b) hinged-hinged; (c) clamped-roll; (d) clamped-simple; (e) clamped-free; and (f) clamped-clamped

Table 5 shows the error of displacement for six types of supports. As in the first case, it was found that the most significant error occurs in the clamped-clamped support, and the smallest error was found in the clamped-free support. In this case, the error is larger.

Table 5 The error of displacement $(E t / E b=20$ and $L / h=4)$

\begin{tabular}{lr}
\hline \multicolumn{1}{c}{ Support } & Error (\%) \\
\hline hinged-roll & 9.367 \\
hinged- hinged & 13.520 \\
clamped -roll & 18.974 \\
clamped -simple & 19.583 \\
clamped-free & 4.432 \\
clamped - clamped & 25.751 \\
\hline
\end{tabular}

\section{Conclusions}

From the analysis, it can be concluded that the performance of DSG elements on FGMs beams yields good results. The convergence results for $k=5 / 6$ and $k$ FGMs are close to the HOSDT reference for the number of elements $\geq 16$. The top and bottom elastic modulus 
$(E t / E b)$ ratio and the power-law index $(n)$ influence the shear correction factor. The greater the $E t / E b$ ratio, the greater the effect of the shear correction factor. In the case with $E t / E b$ $=0.35$ for thick beams $(L / h=4)$, the error of displacement ranged from $0.184 \%$ (clampedfree) to $1.394 \%$ (clamped-clamped). In the case with $E t / E b=20$ for thick beams $(L / h=4)$, the error of displacement ranged from $4.432 \%$ (clamped-free) to $25.751 \%$. (clampedclamped). The largest error occurred in the clamped-clamped support shear energy is more important here than in other supports.

\section{Acknowledgements}

The financial support from Penelitian Dasar Unggulan Perguruan Tinggi 2021 Nomor: NKB-199/UN2.RST/HKP.05.00/2021 is gratefully acknowledged.

\section{References}

Aghazadeh, R., Cigeroglu, E., Dag, S., 2014. Static and Free Vibration Analyses of Small-Scale Functionally Graded Beams Possessing a Variable Length Scale Parameter using Different Beam Theories. European Journal of Mechanics - A/Solids, Volume 46, pp. 111

Benbouras, Y., Maziri, A., Mallil, E., Echaabi, J., 2017. A Nonlinear Analytical Model for Symmetric Laminated Beams in Three-point Bending. International Journal of Technology, Volume 8(3), pp. 437-447

Bletzinger, K.U., Bischoff, M., Ramm, E., 2000. A Unified Approach for Shear-Locking-Free Triangular and Rectangular Shell Finite Elements. Computers \& Structures, Volume 75 (3), pp. 321-334

Hosseini-Hashemi, Sh., Taher, R.D., Akhavan, H., Omidi, M., 2010. Free Vibration of Functionally Graded Rectangular Plates using First Order Shear Deformation Plate Theory. Applied Mathematical Modelling, Volume 34(5), pp. 1276-1291

Irpanni, H., Katili, I., Maknun, I.J., 2017. Development DKMQ Shell Element with Five Degrees of Freedom per Nodal. International Journal of Mechanical Engineering and Robotics Research, Volume 6(3), pp. 248-252

Jing, L.L., Ming, P.J., Zhang, W.P., Fu, L.R., Cao, Y.P., 2016. Static and Free Vibration Analysis of Functionally Graded Beams by Combination Timoshenko Theory and Finite Volume Method. Composite Structures, Volume 138, pp. 192-213

Katili, I., Batoz, J.L., Maknun, I.J., Hamdouni, A., Millet, O., 2014. The Development of DKMQ Plate Bending Element for Thick to Thin Shell Analysis based on Naghdi/Reissner/Mindlin Shell Theory. Finite Elements in Analysis and Design, Volume 100, pp. 12-27

Katili, I., Maknun, I.J., Tjahjon,o E., Alisjahbana, I., 2017. Error Estimation for the DKMQ24 Shell Element using Various Recovery Methods. International Journal of Technology, Volume 8(6), pp. 1060-1069

Katili, I., Batoz, J.L., Maknun, I.J., and Lardeur, P., 2018a. A Comparative Formulation of DKMQ, DSQ and MITC4 Quadrilateral Plate Elements with New Numerical Results based on S-Norm Tests. Computer \& Structure, Volume 204, pp. 48-64

Katili, A.M., Maknun, I.J., Katili, I., 2018b. Theoretical Equivalence and Numerical Performance of T3s and MITC3 Plate Finite Elements. Structural Engineering and Mechanics, Volume 69(5), pp. 527-536

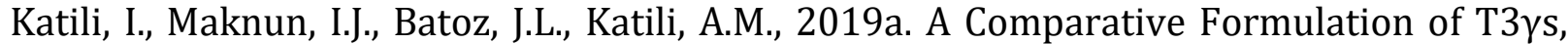
DST, DKMT and MITC3+ Triangular Plate Elements with New Numerical Results based 
on S-Norm Tests. European Journal of Mechanics, A/Solids, Volume 78, https://doi.org/10.1016/j.euromechsol.2019.103826

Katili, I., Maknun, I.J., Millet, O., Hamdouni, A., 2015. Application of DKMQ Element for Composite Plate Bending Structures. Composite Structures, Volume 132, pp. 166-174

Katili, I., Maknun, I.J., Batoz, J.L., Ibrahimbegović, A., 2018c. Shear Deformable Shell Element DKMQ24 for Composite Structures. Composite Structures, Volume 202, pp. 182-200

Katili, I., 2017. Unified and Integrated Approach in a New Timoshenko Beam Element. European Journal of Computational Mechanics, Volume 26(3), pp. 282-308

Katili, I., Maknun, I.J., Batoz, J.L., Katili, A.M., 2018d. Asymptotic Equivalence of DKMT and MITC3 Elements for Thick Composite Plate. Composite Structures, Volume 206, pp. 363-379

Katili, I., Maknun, I.J., Katili, A.M., Bordas, S.P.A., Natarajan, S., 2019b. A Unified Polygonal Locking-Free Thin/Thick Smoothed Plate Element. Composite Structures, Volume 219, pp 147-157

Katili, A.M., Katili, I., 2020. A Simplified UI Element using Third-Order Hermitian Displacement Field for Static and Free Vibration Analysis of FGM Beam. Composite Structures, Volume 250, https://doi.org/10.1016/j.compstruct.2020.112565

Maknun, I.J., Katili, I., Millet, O., Hamdouni, A., 2016. Application of DKMQ24 Shell Element for Twist ff Thin-Walled Beams: Comparison with Vlasov Theory. International Journal for Computational Methods in Engineering Science and Mechanics, Volume 17(6), pp. 391-400

Maknun, I.J., Katili, I., Ibrahimbegović, A., Katili, A.M., 2020. A New Triangular Shell Element for Composites Accounting for Shear Deformation. Composite Structures, Volume 243, https://doi.org/10.1016/j.compstruct.2020.112214

Maknun, I.J., Katili, I., Purnomo, H., 2015. Development of DKMT Element for Error Estimation in Composite Plate Structures. International Journal of Technology, Volume 6(5), pp. 780-789

Malikan, M., Eremeyev, V.A., 2020. A New Hyperbolic-Polynomial Higher-Order Elasticity Theory for Mechanics of thick FGM Beams with Imperfection in the Material Composition. Composite Structures, Volume 249, 112486

Meena R., Tounsi, A., Mouaici, F., Mechab, I., Zidi, M., Bedia, E.A., 2012. Analytical Solutions for Static Shear Correction Factor of Functionally Graded Rectangular Beams. Mechanics of Advanced Materials and Structures, Volume 19(8), pp. 641-652

Nguyen, T-K., Vo, Thuc, P., Thai, H-T., 2013. Static and Free Vibration of Axially Loaded Functionally Graded Beams based on the First-Order Shear Deformation Theory. Composites Part B: Engineering, Volume 55, pp. 147-57

Nguyen, T-K., Sab, K., Bonnet, G., 2008. First-Order Shear Deformation Plate Models for Functionally Graded Materials. Composite Structures, Volume 83(1), pp. 25-36

Reddy, J.N., 2006. An Introduction to the Finite Element Method. New York: McGraw-Hill

Simsek, M., 2009. Static Analysis of a Functionally Graded Beam Under a Uniformly Distributed Load by Ritz Method. International Journal of Engineering and Applied Sciences (IJEAS), Volume 1(3), pp. 3-4

Timoshenko, S., 1922. On the Transverse Vibrations of Bars of Uniform Crosssection. Philosophical Magazine, Volume 43(253), pp. 125-131

Timoshenko, S., 1921. On the Correction for Shear of Differential Equation for Transverse Vibrations of Prismatic Bars. Philosophical Magazine, Volume 41(245), pp. 744-746

Thai, H-T., Vo, T.P., 2012. Bending and Free Vibration of Functionally Graded Beams using Various Higher-Order Shear Deformation Beam Theories. International Journal of Mechanical Sciences, Volume 62(1), pp. 57-66 